Pure Appl. Chem., Vol. 81, No. 6, pp. 1033-1040, 2009.

doi:10.1351/PAC-CON-08-11-14

(C) 2009 IUPAC, Publication date (Web): 24 April 2009

\title{
3-Alkylpyridinium salts from Haplosclerida marine sponges: Isolation, structure elucidations, and biosynthetic considerations ${ }^{\star, * \star}$
}

\author{
Rémi Laville, Philippe Amade, and Olivier P. Thomas ${ }^{\ddagger}$ \\ Université de Nice-Sophia Antipolis, Laboratoire de Chimie des Molécules \\ Bioactives et des Arômes, UMR 6001 CNRS, Faculté des Sciences, 28 Avenue \\ Valrose, F-06108 Nice Cedex 2, France
}

\begin{abstract}
A very little studied marine sponge Callyspongia sp. collected off the coast of Martinique was chemically investigated. The study led to the isolation and structure characterization of two new 3-alkylpyridinium salts which belonged to the recently isolated pachychaline family. Structures were elucidated by 1D, 2D NMR and detailed high-resolution electron spray ionization mass spectra (HRESIMS)-MS studies. The use of HRESIMS-MS studies proved to be highly efficient to identify two other close derivatives in a mixture. Finally, these studies allowed us to propose a general biosynthetic pathway leading to important 3-alkylpyridinium salts.
\end{abstract}

Keywords: sponges; natural products; alkylpyridinium; biosynthesis; mass spectrometry.

\section{INTRODUCTION}

Marine sponges of the order Haplosclerida lack clear specific morphological characteristics which make their taxonomical identification often difficult. In some cases, 3-alkypyridinium salts have shown to be useful chemotaxonomic markers to help in the identification of some species. The chemical studies on sponges of the order Haplosclerida started in 1978 with the work of Schmitz et al. on different species of the genus Haliclona with the aim to identify the compounds responsible for the high ichthyotoxicity of the aqueous extract of this sponge. They were able to isolate the toxic halitoxin, identified as a complex mixture of 3-alkylpyridinium polymeric salts [1]. Other chemical studies performed on Haplosclerida sponges allowed the isolation of a large diversity of 3-alkylpyridinium salts: monomeric, dimeric, and trimeric as well as other polymeric derivatives. Most of them exhibit a wide range of biological activities including cytotoxicity and ichthyotoxicity [2]. Common representatives of this family are the cyclostellettamines [3], the viscosamine [4], or the cyclohaliclonamines [5]. In a recent work on the little studied sponge Pachychalina sp. we were able to isolate three members of a new family of 3-alkylpyridinium salts named pachychalines. They are characterized by bis- and tris-3-alkylpyridinium salts ending by long $\omega$-amino or $\omega$-norspermidino alkyl chains [6]. We report herein our result on the isolation and structure determination of two new pachychalines $\mathbf{1}$ and $\mathbf{2}$ from another undescribed Haplosclerida species of the genus Callyspongia collected off the same Martinique island coasts.

\footnotetext{
* Paper based on a presentation at the $26^{\text {th }}$ International Symposium on Chemistry of Natural Products (ISCNP-26) and $6^{\text {th }}$ International Conference on Biodiversity (ICOB-6), 13-18 July 2008, Charlottetown, Prince Edward Island, Canada. Other presentations are published in this issue, pp. 1001-1129.

**In memory of Dr. Christian Marazano.

¥Corresponding author: Tel.: +33 4 92076134; Fax: +33 4 92076599; E-mail: olivier.thomas@unice.fr
} 
Furthermore, the use of extensive high-resolution electron spray ionization mass spectra (HRESIMS)MS studies was efficient to fully characterize two minor compounds 3 and $\mathbf{4}$. Finally, the structural features of the pachychalines allowed us to draw a common putative biosynthetic pathway for previously described 3-alkylpyridinium salts.

\section{RESULTS AND DISCUSSION}

A specimen of Callyspongia sp. was collected off the northwest coast of the Caribbean island of Martinique by scuba diving. The organism was immediately frozen and kept at $-18{ }^{\circ} \mathrm{C}$ until extraction. The wet specimen was first extracted by $\mathrm{H}_{2} \mathrm{O}$ then by $\mathrm{MeOH} / \mathrm{CH}_{2} \mathrm{Cl}_{2}(1: 1)$. The water extract was dissolved in $\mathrm{MeOH}$, and both organic phases were pooled to give a crude extract which was subsequently subjected to $\mathrm{C}_{18}$ - reversed-phase flash chromatography (eluted with a decreasing polarity gradient of $\mathrm{H}_{2} \mathrm{O} / \mathrm{MeOH}, 1: 0$ to $0: 1$, then $\mathrm{MeOH} / \mathrm{CH}_{2} \mathrm{Cl}_{2}, 1: 0$ to $0: 1$ ). Surprisingly, high-performance liquid chromatography (HPLC)-ESIMS analyses of all fractions gave very similar profiles to those obtained from Pachychalina sp., pachychalines A, B, and C being also detected in the fractions [6]. Because some of the peaks were associated with new masses, we decided to go further into the description of the minor components of this specimen. The $\mathrm{MeOH} / \mathrm{CH}_{2} \mathrm{Cl}_{2}$ (3:1) fraction was consequently purified by $\mathrm{C}_{18^{-}}$reversed-phase semipreparative HPLC to afford the pure new compounds $\mathbf{1}$ and $\mathbf{2}$ together with the new compounds $\mathbf{3}$ and $\mathbf{4}$ in a mixture and the previously described pachychalines $\mathrm{A}, \mathrm{B}$, and $\mathrm{C}$ [6].

Compound 1 was obtained as a colorless oil, and the molecular formula, $\mathrm{C}_{41} \mathrm{H}_{83} \mathrm{~N}_{5}{ }^{+}$, was established by HRESIMS $\left(\mathrm{m} / \mathrm{z}=644.6570[\mathrm{M}]^{+}, \Delta=4.6\right.$ ppm; Fig. 1$)$.

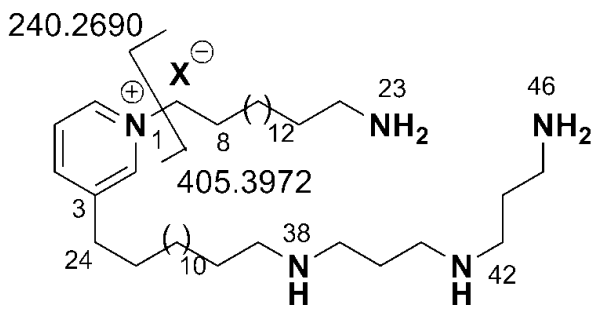

Pachychaline D (1)

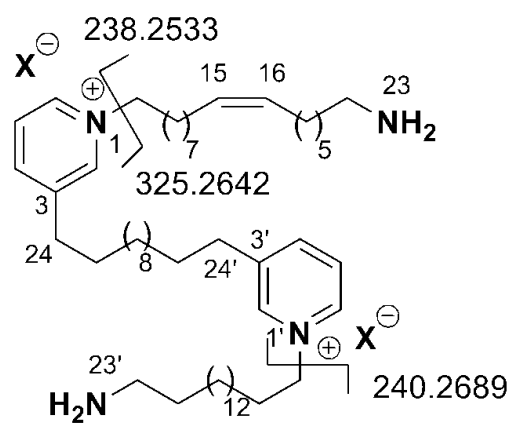

Didehydropachychaline A (2)

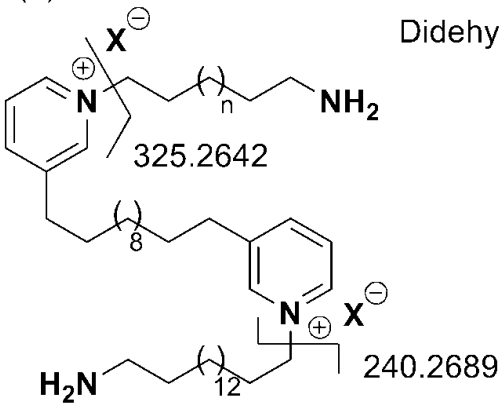

Norpachychaline $A(3) \quad n=11$

Dinorpachychaline $A(4) n=10$

Fig. 1 Structure of the new pachychalines 1-4. 
The UV spectrum $\left(\lambda_{\max }=267 \mathrm{~nm}, \varepsilon=6600 \mathrm{M}^{-1} \mathrm{~cm}^{-1}\right)$ and the ${ }^{1} \mathrm{H}$ NMR spectrum of $\mathbf{1}\left[\delta_{\mathrm{H}}=\right.$ $9.00(\mathrm{~s}, 2 \mathrm{H}, 2-\mathrm{H}), 8.92$ (d, $J=6.0 \mathrm{~Hz}, 2 \mathrm{H}, 6-\mathrm{H}), 8.47$ (d, $J=7.8 \mathrm{~Hz}, 2 \mathrm{H}, 4-\mathrm{H}), 8.00$ (dd, $J=7.8$, $6.0 \mathrm{~Hz}, 2 \mathrm{H}, 5-\mathrm{H}) \mathrm{ppm}$ ] suggested the presence of 3-substituted pyridinium moieties (Table 1). Comparative integration with other signals of aliphatic protons in the ${ }^{1} \mathrm{H}$ NMR spectrum indicated that compound 1 was a mono-3-alkylpyridinium salt. Relative to that of the known pachychalines, the [D6]DMSO (+1 \% TFA) ${ }^{1} \mathrm{H}$ NMR spectrum of $\mathbf{1}$ exhibited characteristic exchangeable $\mathrm{H}-\mathrm{N}$ signals at $\delta_{\mathrm{H}}=7.85$ (br. s, $4 \mathrm{H}$ ), 8.58 (br s., $3 \mathrm{H}$ ), 8.76 (br. s, $3 \mathrm{H}$ ) ppm identical to those of the norspermidine end of pachychaline B [6]. The broad singlet at $\delta_{\mathrm{H}}=7.67$ (br. s, $4 \mathrm{H}$ ) ppm suggested the presence of a unique terminal primary amine.

Table ${ }^{1} \mathrm{H}$ and ${ }^{13} \mathrm{C}$ NMR chemical shifts of pachychaline $\mathrm{D}(\mathbf{1})$ and didehydropachychaline A (2) in [D6]DMSO + 1 \% TFA.

\begin{tabular}{|c|c|c|c|c|}
\hline \multirow[b]{2}{*}{ No. } & \multicolumn{2}{|c|}{1} & \multicolumn{2}{|c|}{2} \\
\hline & $\delta_{\mathrm{C}}(\mathrm{m})$ & $\delta_{\mathrm{H}}(\mathrm{m} J$ in $\mathrm{Hz})$ & $\delta_{\mathrm{C}}(\mathrm{m})$ & $\delta_{\mathrm{H}}(\mathrm{m} J$ in $\mathrm{Hz})$ \\
\hline $2,2^{\prime}$ & $144.1(\mathrm{CH})$ & $9.00(\mathrm{~s})$ & $146.6(\mathrm{CH})$ & $8.90(\mathrm{~s})$ \\
\hline $3,3^{\prime}$ & $143.3(\mathrm{C})$ & & $145.2(\mathrm{C})$ & \\
\hline $4,4^{\prime}$ & $145.2(\mathrm{CH})$ & $8.47(\mathrm{~d} 7.8)$ & $143.3(\mathrm{CH})$ & $8.46(\mathrm{~d} 8.0)$ \\
\hline $5,5^{\prime}$ & $127.7(\mathrm{CH})$ & $8.00(\mathrm{dd} 7.86 .0)$ & $128.9(\mathrm{CH})$ & $8.0(\mathrm{~m})$ \\
\hline $6,6^{\prime}$ & $142.3(\mathrm{CH})$ & $8.92(\mathrm{~d} 6.0)$ & $145.8(\mathrm{CH})$ & $8.82(\mathrm{~d} 6.0)$ \\
\hline $7,7^{\prime}$ & $60.8\left(\mathrm{CH}_{2}\right)$ & $4.54(\mathrm{t} 7.2)$ & $62.9\left(\mathrm{CH}_{2}\right)$ & $4.58(\mathrm{~m})$ \\
\hline $8,8^{\prime}$ & $30.8\left(\mathrm{CH}_{2}\right)$ & $1.90(\mathrm{~m})$ & $32.5\left(\mathrm{CH}_{2}\right)$ & $2.00(\mathrm{~m})$ \\
\hline \multicolumn{5}{|l|}{ 9-13 } \\
\hline $9^{\prime}-13 '$ & $29.0\left(\mathrm{CH}_{2}\right)$ & $1.20-1.40(\mathrm{~m})$ & $29.0\left(\mathrm{CH}_{2}\right)$ & $1.20-1.40(\mathrm{~m})$ \\
\hline 14 & $29.0\left(\mathrm{CH}_{2}\right)$ & $1.20-1.40(\mathrm{~m})$ & $18.1\left(\mathrm{CH}_{2}\right)$ & \\
\hline 15 & $29.0\left(\mathrm{CH}_{2}\right)$ & $1.20-1.40(\mathrm{~m})$ & $130.6(\mathrm{CH})$ & $5.35(\mathrm{~m})$ \\
\hline 16 & $29.0\left(\mathrm{CH}_{2}\right)$ & $1.20-1.40(\mathrm{~m})$ & $130.6(\mathrm{CH})$ & $5.35(\mathrm{~m})$ \\
\hline 17 & $29.0\left(\mathrm{CH}_{2}\right)$ & $1.20-1.40(\mathrm{~m})$ & $18.2\left(\mathrm{CH}_{2}\right)$ & \\
\hline \multicolumn{5}{|l|}{ 18-20 } \\
\hline $14^{\prime}-20^{\prime}$ & $29.0\left(\mathrm{CH}_{2}\right)$ & $1.20-1.40(\mathrm{~m})$ & $29.0\left(\mathrm{CH}_{2}\right)$ & $1.20-1.40(\mathrm{~m})$ \\
\hline $21,21^{\prime}$ & $27.1\left(\mathrm{CH}_{2}\right)$ & $1.50(\mathrm{~m})$ & $27.5\left(\mathrm{CH}_{2}\right)$ & $1.64(\mathrm{~m})$ \\
\hline $22,22^{\prime}$ & $38.9\left(\mathrm{CH}_{2}\right)$ & $2.77(\mathrm{~m})$ & $40.7\left(\mathrm{CH}_{2}\right)$ & $2.87(\mathrm{~m})$ \\
\hline $23,23^{\prime}$ & & 7.67 (br. s) & & 7.67 (br. s) \\
\hline $24,24^{\prime}$ & $31.8\left(\mathrm{CH}_{2}\right)$ & $2.77(\mathrm{~m})$ & $33.6\left(\mathrm{CH}_{2}\right)$ & $2.87(\mathrm{~m})$ \\
\hline $25,25^{\prime}$ & $29.9\left(\mathrm{CH}_{2}\right)$ & $1.62(\mathrm{~m})$ & $31.7\left(\mathrm{CH}_{2}\right)$ & $1.73(\mathrm{~m})$ \\
\hline \multicolumn{5}{|l|}{$26-35$} \\
\hline $26^{\prime}-30^{\prime}$ & $29.0\left(\mathrm{CH}_{2}\right)$ & $1.20-1.40(\mathrm{~m})$ & $29.0\left(\mathrm{CH}_{2}\right)$ & $1.20-1.40(\mathrm{~m})$ \\
\hline 36 & $25.6\left(\mathrm{CH}_{2}\right)$ & $1.55(\mathrm{~m})$ & & \\
\hline 37 & $47.0\left(\mathrm{CH}_{2}\right)$ & $2.87(\mathrm{~m})$ & & \\
\hline 38 & & 8.58 (br. s) & & \\
\hline 39 & $44.3\left(\mathrm{CH}_{2}\right)$ & $2.97(\mathrm{~m})$ & & \\
\hline 40 & $22.6\left(\mathrm{CH}_{2}\right)$ & $1.89(\mathrm{~m})$ & & \\
\hline 41 & $44.2\left(\mathrm{CH}_{2}\right)$ & $2.97(\mathrm{~m})$ & & \\
\hline 42 & & 8.76 (br. s) & & \\
\hline 43 & $44.0\left(\mathrm{CH}_{2}\right)$ & $2.97(\mathrm{~m})$ & & \\
\hline 44 & $24.0\left(\mathrm{CH}_{2}\right)$ & $1.89(\mathrm{~m})$ & & \\
\hline 45 & $36.3\left(\mathrm{CH}_{2}\right)$ & $2.87(\mathrm{~m})$ & & \\
\hline 46 & & 7.85 (br. s) & & \\
\hline
\end{tabular}


In order to assess the length of both alkyl chains but also the location of these alkyl chains around the pyridinium moieties we used extensive HRESIMS-MS studies (Table 2). The usual Hofmann-type fragmentation of pyridinium moieties has appeared as a valuable tool to this end [6]. In the case of compound 1, this fragmentation gave two characteristic monocharged fragments at $\mathrm{m} / \mathrm{z}=405.3972$ $\left(\mathrm{C}_{25} \mathrm{H}_{49} \mathrm{~N}_{4}^{+}\right)$and $240.2690\left(\mathrm{C}_{16} \mathrm{H}_{34} \mathrm{~N}^{+}\right)$, which was in accordance with a $\mathrm{C} 16 \omega$-aminoalkyl chain branched on the nitrogen atom of the pyridinium unit, a $\mathrm{C} 14 \omega$-norspermidinealkyl chain being connected at the C-3 position of the pyridinium. Pachychaline D (1) then appeared as the first example of a monopyridinium pachychaline.

Table 2 ESI(+) HRMS-MS data of compounds 1-4.

\begin{tabular}{|c|c|c|c|c|}
\hline \multirow[b]{2}{*}{ Compound } & \multicolumn{2}{|c|}{ ESI(+) HRMS } & \multicolumn{2}{|c|}{ ESI(+) HRMS-MS } \\
\hline & $\begin{array}{c}\text { Fragment ion } \\
\mathrm{m} / \mathrm{z}\end{array}$ & $\begin{array}{l}\text { Molecular formula } \\
\text { (deviation in ppm }\end{array}$ & $\begin{array}{c}\text { Fragment ion } \\
\qquad \mathrm{m} / z\end{array}$ & $\begin{array}{l}\text { Molecular formula } \\
\text { (deviation in ppm) }\end{array}$ \\
\hline 1 & 644.6570 & $\mathrm{C}_{41} \mathrm{H}_{83} \mathrm{~N}_{5}{ }^{+}$(4.6) & $\begin{array}{l}240.2690 \\
405.3972\end{array}$ & $\begin{array}{l}\mathrm{C}_{16} \mathrm{H}_{34} \mathrm{~N}^{+}(1.7) \\
\mathrm{C}_{25} \mathrm{H}_{49} \mathrm{~N}_{4}^{+}(4.5)\end{array}$ \\
\hline 2 & 401.3888 & $\mathrm{C}_{54} \mathrm{H}_{98} \mathrm{~N}_{4}{ }^{2+}(-0.5)$ & $\begin{array}{l}238.2533 \\
240.2689 \\
325.2642\end{array}$ & $\begin{array}{l}\mathrm{C}_{16} \mathrm{H}_{32} \mathrm{~N}^{+} \\
\mathrm{C}_{16}{ }_{16} \mathrm{H}_{34} \mathrm{~N}^{+}(1.5) \\
\mathrm{C}_{22} \mathrm{H}_{33} \mathrm{~N}_{2}{ }^{+}(1.1)\end{array}$ \\
\hline 3 & 395.3907 & $\mathrm{C}_{53} \mathrm{H}_{98} \mathrm{~N}_{4}{ }^{2+}$ (4.1) & $\begin{array}{l}226.2534 \\
240.2690 \\
325.2646\end{array}$ & $\begin{array}{l}\mathrm{C}_{15} \mathrm{H}_{32} \mathrm{~N}^{+}(2.0) \\
\mathrm{C}_{16}{ }_{16} \mathrm{H}_{34} \mathrm{~N}^{+}(1.8) \\
\mathrm{C}_{22} \mathrm{H}_{33} \mathrm{~N}_{2}{ }^{+}(2.5)\end{array}$ \\
\hline 4 & 388.3827 & $\mathrm{C}_{52} \mathrm{H}_{96} \mathrm{~N}_{4}^{2+}(4.0)$ & $\begin{array}{l}212.2377 \\
240.2690 \\
325.2642\end{array}$ & $\begin{array}{l}\mathrm{C}_{14} \mathrm{H}_{30} \mathrm{~N}^{+} \\
\mathrm{C}_{16} \mathrm{H}_{34} \mathrm{~N}^{+}(1.8) \\
\mathrm{C}_{22}{ }_{2} \mathrm{H}_{33} \mathrm{~N}_{2}{ }^{+}(1.3)\end{array}$ \\
\hline
\end{tabular}

Compound 2 was obtained as a colorless oil, and the molecular formula, $\mathrm{C}_{54} \mathrm{H}_{98} \mathrm{~N}_{4}{ }^{2+}$, was established by HRESIMS $\left(\mathrm{m} / \mathrm{z}=401.3888[\mathrm{M}]^{2+}, \Delta=-0.5 \mathrm{ppm}\right.$; Fig. 1). The ${ }^{1} \mathrm{H}$ and ${ }^{13} \mathrm{C}$ NMR spectra of compound 2 were very similar to those of pachychaline A, and the integration pattern evidenced a bis-3-alkylpyridinium salt. The difference between the spectra of both compounds came from the appearance of signals at $\delta_{\mathrm{H}}=5.35$ (br. s, $2 \mathrm{H}$ ) and $\delta_{\mathrm{C}}=130.6$ for 2 , which suggested the presence of a disubstituted double bond far from the ends of one of the three alkyl chains. The HRESIMS-MS fragments were useful to identify the unsaturated alkyl chain, to determine the length of the three alkyl chains, and to assess the "C-C" or " $\mathrm{C}-\mathrm{N}$ " connection between both cycles. Pachychaline A and compound 2 exhibited the same fragments $\mathrm{C}_{16} \mathrm{H}_{34} \mathrm{~N}^{+}$and $\mathrm{C}_{22} \mathrm{H}_{33} \mathrm{~N}_{2}{ }^{+}$, which proved a " $\mathrm{C}-\mathrm{C}$ " connection between both cycles through a $\mathrm{C} 12$ central alkyl chain and a $\mathrm{C} 16 \omega$-amino alkyl chain. The appearance of a new $\mathrm{C}_{16} \mathrm{H}_{32} \mathrm{~N}^{+}$fragment was consistent with a monounsaturated $\mathrm{C} 16 \omega$-amino alkyl chain. An oxidative cleavage of the double bond with $\mathrm{OsO}_{4} / \mathrm{NaIO}_{4}$ was used to locate the unsaturation in the $\omega$-amino alkyl chain. The observation by HPLC-MS of a double charged compound at $\mathrm{m} / \mathrm{z} 353.3$ was indicative of the loss of a $-\left(\mathrm{CH}_{2}\right)_{7}-\mathrm{NH}_{2}$ end. The stereochemistry of the double bond was further deduced from characteristic ${ }^{13} \mathrm{C}$ chemical shifts of the carbons $\alpha$ to the double bond at $\delta_{\mathrm{C}}=28.1$ and $28.2 \mathrm{ppm}$, which indicated a $Z$ configuration. In consequence, compound 2 was named didehydropachychaline A.

During the purification process other peaks were collected, but they were shown to be a mixture of 3-alkylpyridinium salts by MS. Because mass quantity was a limiting factor which impeded purification, we thought that HRESIMS-MS studies would be a valuable tool to fully characterize compounds of this family in a mixture. The molecular formula, $\mathrm{C}_{53} \mathrm{H}_{98} \mathrm{~N}_{4}{ }^{2+}$ of compound $\mathbf{3}$ was established by HRESIMS $\left(\mathrm{m} / z=395.3907[\mathrm{M}]^{2+}, \Delta=-4.1 \mathrm{ppm}\right.$; Fig. 1$)$. This molecular formula indicated the loss of a methylene unit from pachychaline A. The fragmentation pattern obtained by HRESIMSMS allowed its location among the three alkyl chains. Indeed, the $\mathrm{C}_{15} \mathrm{H}_{32} \mathrm{~N}^{+}, \mathrm{C}_{16} \mathrm{H}_{34} \mathrm{~N}^{+}$, and 
$\mathrm{C}_{22} \mathrm{H}_{33} \mathrm{~N}_{2}{ }^{+}$fragments confirmed the " $\mathrm{C}-\mathrm{C}$ " connection between both pyridinium chains through a central C12 alkyl chain but also the presence of a C16 $\omega$-amino alkyl chain and a C15 $\omega$-amino alkyl chain. Compound 3 was consequently named norpachychaline $A$. The molecular formula, $\mathrm{C}_{52} \mathrm{H}_{96} \mathrm{~N}_{4}{ }^{2+}$ of compound 4 was established by HRESIMS $\left(\mathrm{m} / z=388.3827[\mathrm{M}]^{2+}, \Delta=-4.0 \mathrm{ppm}\right.$; Fig. 1$)$. This molecular formula indicated the loss of two methylene units from pachychaline $\mathrm{A}$, and the fragmentation pattern obtained by HRESIMS-MS allowed their location among the three alkyl chains. Indeed, the $\mathrm{C}_{14} \mathrm{H}_{30} \mathrm{~N}^{+}, \mathrm{C}_{16} \mathrm{H}_{34} \mathrm{~N}^{+}$, and $\mathrm{C}_{22} \mathrm{H}_{33} \mathrm{~N}_{2}^{+}$fragments confirmed the " $\mathrm{C}-\mathrm{C}$ " connection between both pyridinium chains through a central $\mathrm{C} 12$ alkyl chain but also the presence of a $\mathrm{C} 16 \omega$-amino alkyl chain and a $\mathrm{C} 14 \omega$-amino alkyl chain.

This study enabled us to extend the pachychaline family by the isolation of the first mono-3alkylpyridinium salt, namely, pachychaline D (1). Characterization of didehydro-, nor-, and dinorpachychaline $\mathrm{A}(\mathbf{2}, \mathbf{3}$, and $\mathbf{4})$ also proved the nonspecificity of the enzymatic process leading to the alkyl chains. Turning now to biosynthetic considerations, the fatty acid origin of the $\mathrm{C} 15$ alkyl chain of norpachychaline A (3) cannot be ruled out and can easily be explained by a decarboxylation during the elongation process. Such a conclusion has been the result of biosynthetic studies performed on haminol by the group of Fontana [7]. More important was the isolation of pachychaline D (1) which could be an intermediate in the biosynthesis of pachychaline A but also pachychaline B using the same hypotheses made during our study of Pachychalina sp. [6]. There are only a few biosynthetic considerations made on the pyridinium constructions, and our hypothesis is closely derived from conclusions following the biomimetic work of Marazano [8] and Baldwin [9] who first identified the key role of C3 subunits like malonaldehyde or acrolein as key precursors in the biosynthesis of 3-alkylpyridinium salts. In our case, we believe that the $\mathrm{C} 3$ subunits would come from the norspermidine ends of biosynthetic intermediates. Two sets of key reactions would allow the constructions of the very large family of 3-alkylpyridinium salts (Scheme 1). The first transformation named "tertiary amine formation" would occur only on the first secondary amine of the norspermidine end through oxidation of an inter- or intra-primary amine and reductive amination of the subsequent imine. This would be the key transformation leading to polymerization or macrocyclization. The second key transformation would be related to the pyridine or

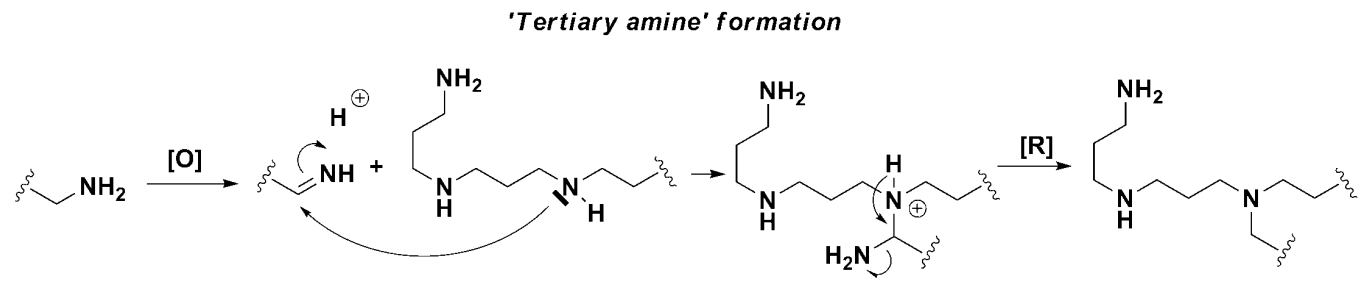

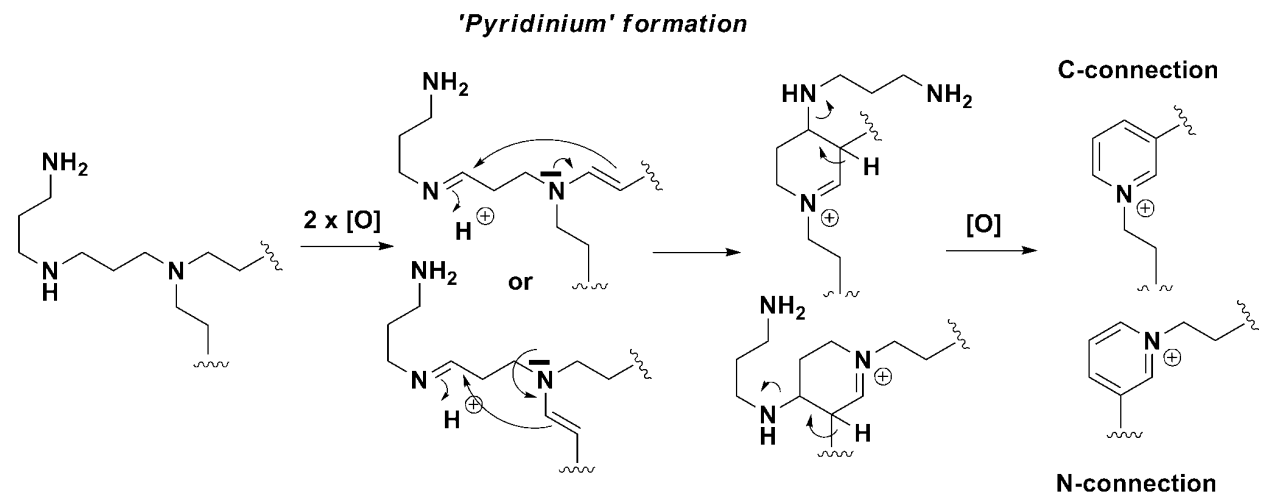

Scheme 1 Two key transformations in the putative biosynthesis of 3-alkylpyridiniums salts. 
"pyridinium formation". Our assumption involves oxidations of the first and second amines of a norspermidine end and cyclization of the enamine of the first amine on the imine of the second. Subsequent elimination and oxidation would lead to the pyridine or pyridinium moiety.

This hypothesis was further supported by the isolation of two types of connections between alkylpyridinium cycles: a $\mathrm{C}-\mathrm{C}$ or a $\mathrm{C}-\mathrm{N}$ connection. These two different connections could easily been explained by two possible enamine formation on the first amine of the norspermidine. A branched enamine formation and reaction would lead to a classical $\mathrm{C}-\mathrm{N}$ connection while a linear enamine formation would lead to a $\mathrm{C}-\mathrm{C}$ connection.

We then tried to expand our hypothesis on other groups of 3-alkylpyridium salts (Scheme 2). The previously isolated motuporamines would be obtained after intramolecular tertiary amine formation
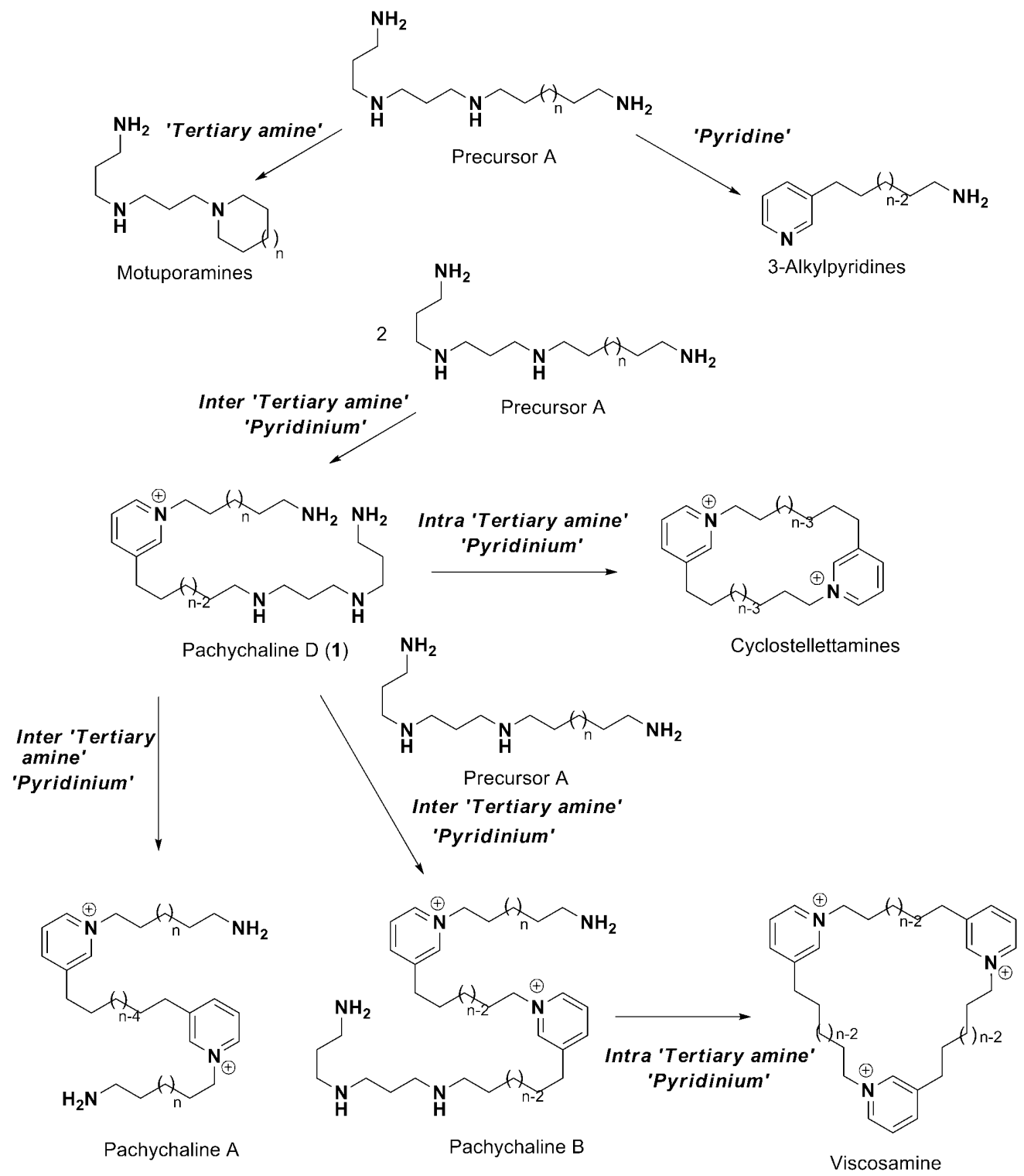

Scheme 2 Biosynthetic considerations in the 3-alkylpyridinium family. 
[10]. The 3-alkylpyridine family (e.g., niphatesines) would be synthesized starting from the same precursor which would undergo an oxidative cyclization at the norspermidine end [11]. The new key pachychaline D (1) would be obtained by a tertiary amine formation from two precursors A followed by pyridinium formation. Repeating this process in an intramolecular way would give access to the large family of the cyclostellettamines [12]. The condensation of a third molecule of the same precursor A would give access to a larger diversity. Pachychalines A and B would be obtained depending on the type of pyridinium formation: "C-C" or "C-N" connection. Three successive tertiary amine/pyridinium formation processes ending in an intramolecular manner would give access to the recently isolated viscosamine [13]. Pachychaline $\mathrm{C}$ would even be the result of the alkylation of a fourth unit followed by an oxidative cyclization [6]. The generalization of these processes to different known families of 3-alkylpyridinium salts strongly supported our hypothesis of a unique precursor and two key transformations in the biosynthesis of these complex structures.

All these results also stress the importance of the HRESIMS-MS tool in the structure determination of 3-alkylpyridinium salts. They demonstrated that the same salts could be found in two different species and then suggested a symbiotic origin for these molecules. Finally, these studies gave more support to our first hypothesis on the biosynthetic origin of 3-alkylpyridinium salts and on the key role on norspermidine moiety into the pyridinium biosynthesis.

\section{EXPERIMENTAL SECTION}

\section{General}

All solvents and reagents were used as received unless otherwise noted. ${ }^{1} \mathrm{H}$ and ${ }^{13} \mathrm{C}$ NMR spectra were recorded with a Bruker Avance $500 \mathrm{MHz}$ spectrometer. Chemical shifts $(\delta)$ are recorded in ppm with [D6]DMSO $\left(\delta_{\mathrm{H}}=2.50 \mathrm{ppm}\right.$ and $\left.\delta_{\mathrm{C}}=39.5 \mathrm{ppm}\right)$ as internal standard with multiplicity (s singlet, d doublet, $\mathrm{t}$ triplet, q quartet, quint quintuplet, $\mathrm{m}$ multiplet, br. broad). ESI mass spectra were obtained with a Bruker Esquire 3000 Plus spectrometer in the positive ornegative mode. High-resolution mass spectra and HRMS-MS were obtained from an LTQ Orbitrap (Thermo Finnigan) spectrometer in the positive mode. IR spectra were obtained with a Perkin-Elmer Paragon 1000 FT-IR spectrometer.

\section{Extraction and isolation}

Callyspongia sp. was collected off the northwest coast of the island of Martinique by scuba diving. The specimen was immediately frozen and kept at $-18{ }^{\circ} \mathrm{C}$ until extraction. The wet specimen $(650 \mathrm{~g})$ was desalted with water $(1000 \mathrm{ml})$ then extracted with $\mathrm{MeOH} / \mathrm{CH}_{2} \mathrm{Cl}_{2}(1: 1 ; 2 \times 1000 \mathrm{ml})$. The aqueous phase was evaporated then extracted by $\mathrm{MeOH}(1000 \mathrm{ml})$ and both organic phases were gathered and evaporated to give the crude extract ( $42 \mathrm{~g}$ ). The resulting oil was subjected to $\mathrm{C} 18$ reversed-phase flash chromatography (eluted with a decreasing polarity gradient of $\mathrm{H}_{2} \mathrm{O} / \mathrm{MeOH}, 1: 0$ to $0: 1$, then $\mathrm{MeOH} / \mathrm{CH}_{2} \mathrm{Cl}_{2}, 1: 0$ to $0: 1$ ). The subsequent $\mathrm{MeOH} / \mathrm{CH}_{2} \mathrm{Cl}_{2}$ (3:1) fraction was further purified by semipreparative reversed-phase HPLC (Phenomenex, Luna C18, $250 \times 10 \mathrm{~mm}, 5 \mu \mathrm{m}, \mathrm{MeOH} / \mathrm{H}_{2} \mathrm{O} / \mathrm{TFA}$, 60:40:0.1 to 80:20:0.1) to afford pure compounds 1 ( $2.5 \mathrm{mg}, 0.003 \%$ wet weight) and 2 (1.5 mg, $0.002 \%$ wet weight), together with 3 and $\mathbf{4}$ in a mixture $(0.7 \mathrm{mg})$.

Pachychaline D (1): Colorless oil. ${ }^{1} \mathrm{H}$ NMR $(500 \mathrm{MHz},[\mathrm{D} 6] \mathrm{DMSO})$ and ${ }^{13} \mathrm{C}$ NMR $(125 \mathrm{MHz}$, [D6]DMSO) see Table 1. UV (MeOH): $\lambda_{\text {max }}\left(\varepsilon, \mathrm{M}^{-1} \mathrm{~cm}^{-1}\right)=267$ (6600) nm. HRMS (ESI+): see Table 2.

Didehydropachychaline A (2): Colorless oil. ${ }^{1} \mathrm{H}$ NMR (500 MHz, [D6]DMSO) and ${ }^{13} \mathrm{C}$ NMR (125 MHz, [D6]DMSO) see Table 1. UV $(\mathrm{MeOH}): \lambda_{\max }\left(\varepsilon, \mathrm{M}^{-1} \mathrm{~cm}^{-1}\right)=267(6600) \mathrm{nm}$. HRMS (ESI+): see Table 2.

Norpachychaline A (3) and dinorpachychaline A (4): HRMS (ESI+): see Table 2.

Oxidative cleavage of didehydropahychaline A (2): HPLC-MS (ESI+): $\mathrm{m} / z=353.2[\mathrm{M}]^{2+}$. 


\section{ACKNOWLEDGMENTS}

We are grateful to PharmaMar Madrid for financial support also provided by a grant (R. L.) of the Provence-Alpes-Côte d'Azur Region and the CNRS. We thank J. Vacelet for careful taxonomical sponge identification, M. Gaysinski for assistance in recording the NMR spectroscopic experiments, and J.-M. Guigonis for assistance in recording the HRMS and HRMS-MS experiments. We finally thank Mr le préfet de la Martinique and the DIREN for their help in the collection of Caribbean marine invertebrates.

\section{REFERENCES}

1. F. J. Schmitz, K. H. Hollenbeak, D. C. Campbell. J. Org. Chem. 43, 3916 (1978).

2. For reviews on 3-alkylpyridinium salts, see: (a) K. Sepcik. J. Toxicol., Toxin Rev. 19, 13960 (2000); (b) R. J. Andersen, R. W. van Soest, F. Kong. "Alkaloids" in Chemical and Biological Perspectives, Vol. 10, S. W. Pelletier (Ed.), pp. 301-355, Pergamon, Elsevier Science, Oxford (1996); (c) K. Sepcik, T. Turk. Prog. Mol. Subcell. Biol. 42, 105 (2006).

3. (a) N. Fusetani, N. Asai, S. Matsunaga. Tetrahedron Lett. 23, 3967 (1994); (b) J. H. H. L. De Oliveira, A. Grube, M. Köck, R. G. S. Berlinck, M. L. Macedo, A. G. Ferreira, E. Hajdu. J. Nat. Prod. 67, 1685 (2004).

4. C. A. Volk, M. Köck. Org. Lett. 5, 3567 (2003).

5. T. Teruya, K. Kobayashi, K. Suenaga, H. Kigoshi. J. Nat. Prod. 69, 135 (2006).

6. R. Laville, O. P. Thomas, F. Berrué, F. Reyes, P. Amade. Eur. J. Org. Chem. 121 (2008).

7. A. Cutignano, A. Tramice, S. De Caro, G. Villani, G. Cimino, A. Fontana. Angew. Chem., Int. Ed. 42, 2633 (2003).

8. J. E. Baldwin, T. D. W. Claridge, A. J. Culshaw, F. A. Heupel, V. Lee, D. R. Spring, R. C. Whitehead, R. J. Boughtflower, I. M. Mutton, R. J. Upton. Angew. Chem., Int. Ed. 37, 2661 (1998).

9. A. Kaiser, X. Billot, A. Gateau-Olesker, C. Marazano, B. C. Das. J. Am. Chem. Soc. 120, 8026 (1998).

10. D. E. Williams, P. Lassota, R. J. Andersen. J. Org. Chem. 63, 4838 (1998).

11. J. Kobayashi, C. M. Zeng, M. Ishibashi, H. Shigemori, T. Sasaki, Y. Mikami. J. Chem. Soc., Perkin Trans. 11291 (1992).

12. N. Fusetani, N. Asai, S. Matsunaga, K. Honda, K. Yasumuro. Tetrahedron Lett. 35, 3967 (1994).

13. C. A. Volk, M. Koeck. Org. Lett. 5, 3567 (2003). 